driven by rage, quoting Polybius' harrowing description of Roman soldiers engaged in such furious slaughter that they sliced dogs in two (10.14.4-6). There is a great deal to say about the rôle of anger in the Romans' conflicted representations of themselves as models of both self-restraint and aggressive soldiery; but here H. simply lists another Polybius reference, with minimal comment $(6.52$, on p. 197). The same goes for his treatment of anger in oratory, a good example of the importance of making a big show of uncontrolled rage in certain controlled circumstances. But let these complaints stand as proof of the book's power to provoke further study.

A final note. The link $\mathrm{H}$. draws between anger control and civil society (a phrase he uses in a very broad sense) is a matter of central importance nowadays to thinkers and policy makers all over the political spectrum, such as Judith Shklar and Alan Wolfe, who believe that widespread tolerance of lapses in civility, especially bursts of uncontrolled rage, creates conditions under which citizens passively accept higher rates of violence from their fellows and from the state itself. Though $\mathrm{H}$. rarely mentions contemporary applications of his study (the last few pages are an exception), his writing shares with theirs an invigorating sense of relevance, even urgency. His book should be widely read.

Stanford University

JOY CONNOLLY

\title{
ROMAN HONOUR
}

C. A. Barton: Roman Honor. The Fire in the Bones. Pp. xiii +326. Berkeley, Los Angeles, and London: University of California Press, 2001. Cased, \$47.50. ISBN: 0-520-22525-2.

This work sets out to gain insight into ancient Roman experiences of the emotions associated with honor, the internal flame that provided the stimulus for much Roman social interaction and behaviour. Barton collects a vast range of citations from Roman literature as raw materials for a multi-layered portrait of this aspect of Roman culture; her stated aim is to foreground this multiplicity of Roman voices and to let them 'speak for themselves' (p. 17). Her investigation of ancient culture is illuminated with juxtapositions of comparative material from diverse sources (within the first few pages: Nazi Germany, medieval Spain, contemporary America, Africa, and India), and by viewing Roman concepts variously through lenses of contemporary approaches in other disciplines, particularly anthropology and psychology.

The result is a powerful contribution to the growing body of studies concerned with investigating the inner experience of the ancient Romans. It seeks to expose the mechanisms by which such internal forces as a sense of honour and shame, desire for glory or for protection of reputation, or the need to display virtue publicly, governed society and individuals - in the absence, for instance, of a formal police force (pp. 18-28). However, the work explicitly seeks to reach beyond an audience of classicists, and to show how conclusions about the workings of Roman honor have broader significance for our understanding of the human race: 'I have written this book in part because I think it is possible to see through the lens of ancient Roman society the obliquities of our own notions of honour' (p. 271, see also the conclusion and the 'Philosophical Coda' of pp. 289-95). With its 'applied classics', then, this is an ambitious and exciting book, combining wide reference to ancient material with an eye for fertile interdisciplinarity and a sense of the big picture.

(C) The Classical Association, 2003 
The main body of the book is divided into three parts, which explore in turn the concepts of honour put to the test, confession, and shame. Titles of chapters within these sections (e.g. 'Light and Fire', 'Stone and Ice', 'The Poise of Shame', and 'The Poison of Shame') give a flavour both of the prose style - stylish, descriptive, self-aware - and of the methodology: a series of impressionistic mosaics depicting the metaphors through which Romans formulated their experiences of honor. There is an overarching narrative about the breakdown of the warrior code under the late republic and early empire, but the analysis switches between diachronic and synchronic.

Terms such as 'dazzling' or 'brilliant' are appropriate (and indeed are employed by other scholars on the cover of the book), and they suggest why this work is at once impressive and unsatisfying. It dazzles partly because it does not allow one beneath the surface of its argument; there is no sense of how the Roman texts have led the author to the ideas which she lays out, and it is therefore difficult to engage with them except on the most superficial and generalized level. The profusion of sources piled high in the main text and footnotes is bewildering; texts are presented as glittering fragments, shorn of their literary and historical context (e.g. we surely need guidance in interpreting the citation from Plautus Captivi on p. 69). Very different sources are juxtaposed without comment. There are no sustained readings of passages, and although B. talks about the nuances of language, she does not explore this aspect of her texts. The sources appear as cleverly selected 'soundbites', and inevitably the voices of the Romans themselves are not heard 'speaking for themselves' above the voice of B. herself.

All this is frustrating for the pedestrian classicist interested in pursuing details of the argument. One craves organization, explanation, and analysis of the source material. The effect of the work is disorientating; the book could well have done with an index of authors and passages cited, enabling the reader to rebuild some kind of context for herself. However, B. is candid about her methodology-'unscientific strategies for orchestrating disorder' - and its drawbacks, and reading this book on its own terms is a rewarding experience. The work offers stimulating insights, refreshing perspectives, and fruitful comparisons, and for those interested in Roman culture, and more broadly in the history of emotion and honour, it will prove a provocative and at times exhilarating read.

University of Exeter

REBECCA LANGLANDS

\section{STATUES IN GREEK LITERATURE}

\section{T. Steiner: Images in Mind: Statues in Archaic and Classical Greek Literature and Thought. Pp. xviii +360 , ills. Princeton and Oxford: Princeton University Press, 2001. Cased, \$39.50. ISBN: 0-691-04431-7.}

Early in her provocative and insightful new book (p. 79), Debra Steiner discusses Heraclitus' famous derision of his fellow Greeks for worshiping statues 'as if chattering with houses, not recognizing what gods or even heroes are like' (B5 DK). The fragment, $\mathrm{S}$. argues, is no less shrewd than ungenerous: it 'succinctly expresses the way Greeks . . . commonly imagined the relationship between the god (or hero) and his visual representation, and has acknowledged the concept underpinning the efficacy ascribed to images venerated in cult'. S.'s attention to 'efficacy' hints at the

(C) The Classical Association, 2003 